\title{
Surface-Enhanced Raman Spectroscopy with High Spatial Resolution
}

\author{
T.R. Huser
}

February 4, 2003

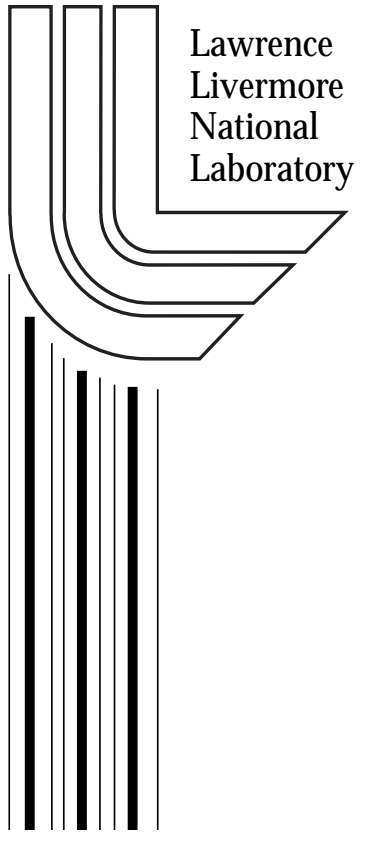




\section{DISCLAIMER}

This document was prepared as an account of work sponsored by an agency of the United States Government. Neither the United States Government nor the University of California nor any of their employees, makes any warranty, express or implied, or assumes any legal liability or responsibility for the accuracy, completeness, or usefulness of any information, apparatus, product, or process disclosed, or represents that its use would not infringe privately owned rights. Reference herein to any specific commercial product, process, or service by trade name, trademark, manufacturer, or otherwise, does not necessarily constitute or imply its endorsement, recommendation, or favoring by the United States Government or the University of California. The views and opinions of authors expressed herein do not necessarily state or reflect those of the United States Government or the University of California, and shall not be used for advertising or product endorsement purposes.

This work was performed under the auspices of the U. S. Department of Energy by the University of California, Lawrence Livermore National Laboratory under Contract No. W-7405-Eng-48.

This report has been reproduced directly from the best available copy.

Available electronically at http://www.doc.gov/bridge

Available for a processing fee to U.S. Department of Energy

And its contractors in paper from

U.S. Department of Energy

Office of Scientific and Technical Information

P.O. Box 62

Oak Ridge, TN 37831-0062

Telephone: (865) 576-8401

Facsimile: (865) 576-5728

E-mail: reports@adonis.osti.gov

Available for the sale to the public from

U.S. Department of Commerce

National Technical Information Service

5285 Port Royal Road

Springfield, VA 22161

Telephone: (800) 553-6847

Facsimile: (703) 605-6900

E-mail: orders@ntis.fedworld.gov

Online ordering: http://www.ntis.gov/ordering.htm

OR

Lawrence Livermore National Laboratory

Technical Information Department's Digital Library

http://www.llnl.gov/tid/Library.html 
The identification of individual molecules and the determination of how these interact with their local environment are critical steps toward a better understanding of complex organic systems. Optical detection techniques have always played a key role in the nondestructive and noninvasive analysis of complex materials. Until recently, however, optical microscopy has lacked the sensitivity to study processes on the molecular scale. This has changed with the recent development of new schemes that limit the optical detection volume, and the advent of new, highly quantum-efficient photon detectors. These inventions have enabled researchers to optically probe biomolecular processes at the single molecule level by observing the fluorescence of specific marker molecules. The requirement to specifically label biomolecules and the fact, that fluorescence emission is prone to photodecomposition of the marker molecules, however, have limited this approach to a few, well-characterized case studies. Raman scattering, is one of few optical techniques that can identify atomic species and in addition determine their chemical bonds by observing their distinct vibrational fingerprints; but it is orders of magnitude weaker than fluorescence.

In this project, we have developed new optical probes that allow for the non-destructive characterization and identification of organic and inorganic matter at the single molecule level by surface-enhanced Raman spectroscopy. Our approach combines confocal Raman microscopy with surface-enhanced Raman spectroscopy (SERS) generated by coating scanning probe microscope (SPM) tips with thin (30$40 \mathrm{~nm}$ ) gold and silver films. The scanning SERS probe generates an image of the physical structure of a sample together with detailed chemical information about its composition. In a complementary approach, we have also used gold or silver nanoparticles to generate SER spectra from single molecules adsorbed to these particles. This project has led to the development of a new capability at LLNL, i.e. the field of optical single molecule detection.

During the initial phase of this project, we have developed and optimized our optical detection setup, which has allowed us to follow the photophysics of single fluorescent molecules with high temporal and spatial resolution. This optimization has enabled us to perform spectroscopy on single fluorescent molecules with integration times per spectrum as low as 5 seconds and to simultaneously obtain intensity-transients with millisecond time resolution. This capability has enabled us to study the energy transfer mechanism in aggregated molecules of conjugated polymers with unprecedented temporal and spectral resolution[1,2]. Figure 1 provides an overview of some of these results. Figure 1a shows the spectrum of a single molecule of Poly[2-methoxy,5-(2'-ethyl-hexyloxy)-p-phenylene-vinylene] (MEHPPV, see the inset for the chemical structure), a conjugated polymer with an average molecular weight of 1,000,000. This molecule was prepared from toluene as a solvent. The non-polar solvent toluene leads to self-aggregation of these polymer molecules as demonstrated by the well resolved vibrational structure of the single molecule spectrum. This aggregation leads to $100 \%$ intramolecular energy transfer efficiency and causes the intensity to jump to the background level (see figure 1b) whenever a reversible quenching defect site was created by excited-state photoreactions within the molecule. Molecules prepared from the more polar solvent chloroform tend to assume an open chain conformation. In this conformation energy transfer is restricted to the much slower energy migration along the chain which gives rise to a broad spectral emission as shown in figure 1c. The intensity transient now shows the typical exponential photobleaching behavior that is expected for multichromophoric molecules (figure 1d). We have successfully applied this newly achieved sensitivity to a number of fluorescing quantum system among which are single chromophores, single semiconductor nano-crystals and the just discussed single multichromophoric polymer molecules. 

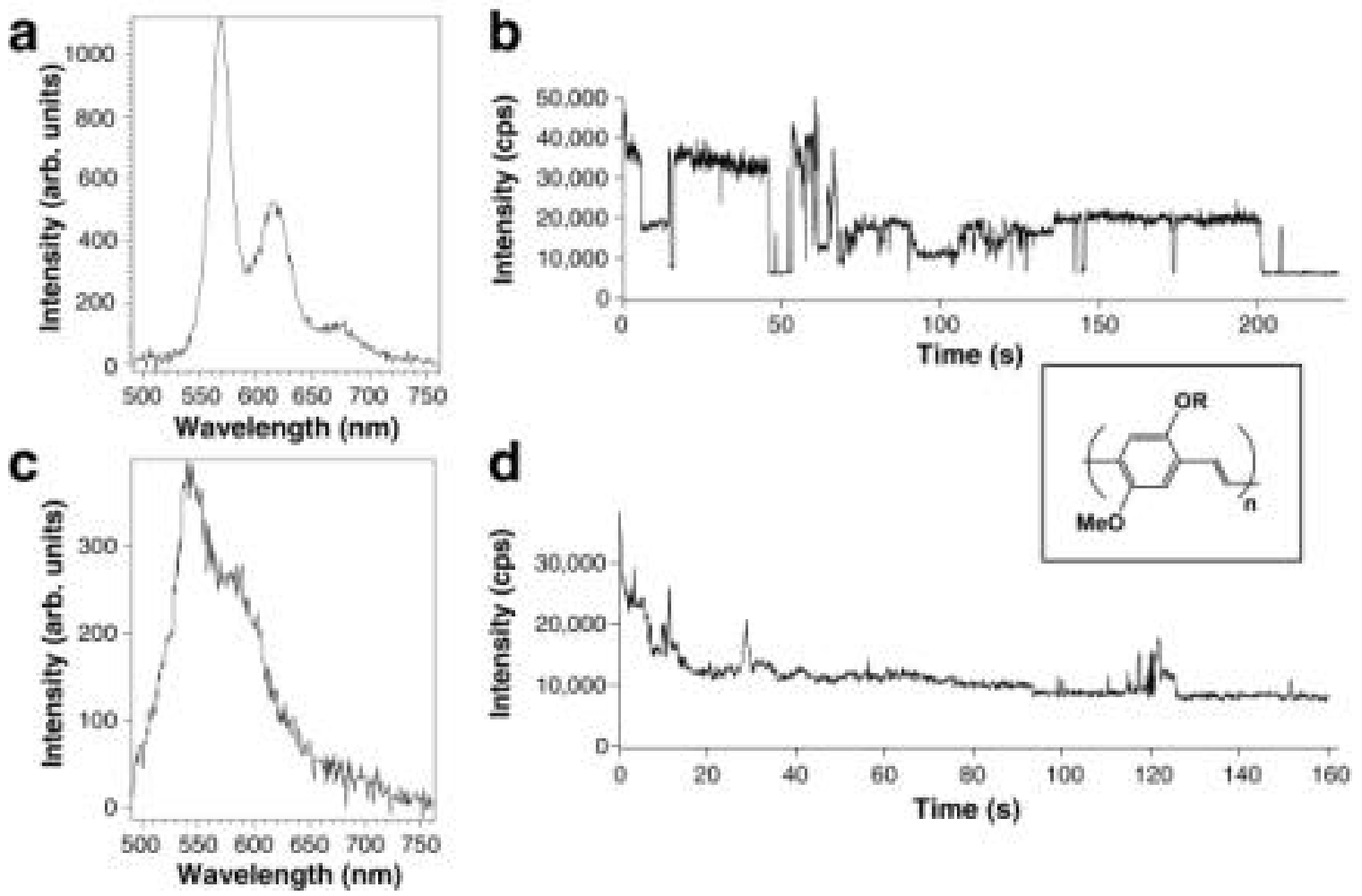

Figure 1: a) Spectrum of a MEH-PPV molecule prepared from toluene solution. b) Intensity transient for the same molecule as in a). c) Spectrum of a MEH-PPV molecule prepared from chloroform solution. d) Intensity transient for the same molecule as in c). Inset shows the chemical structure of MEH-PPV.

After successful completion of this step, we have begun to use this setup as a confocal micro-Raman system, which allows us to obtain Raman spectra with an excellent signal-to-noise ratio even from the interior of single biological cells (see figure 2) [3]. We have then begun to characterize the SER spectra of single biological molecules that were physisorbed to gold or silver nanoparticles. The results from this study have allowed us to measure the distance-dependence of SERS by comparing experimental SERS spectra of the amino acid glycine obtained from gold nanoparticles to molecular dynamics calculations of glycine adsorption to gold surfaces. We also studied the fluctuations of DNA hairpin molecules attached to gold nanoparticles as a model system for macromolecular conformational changes. 

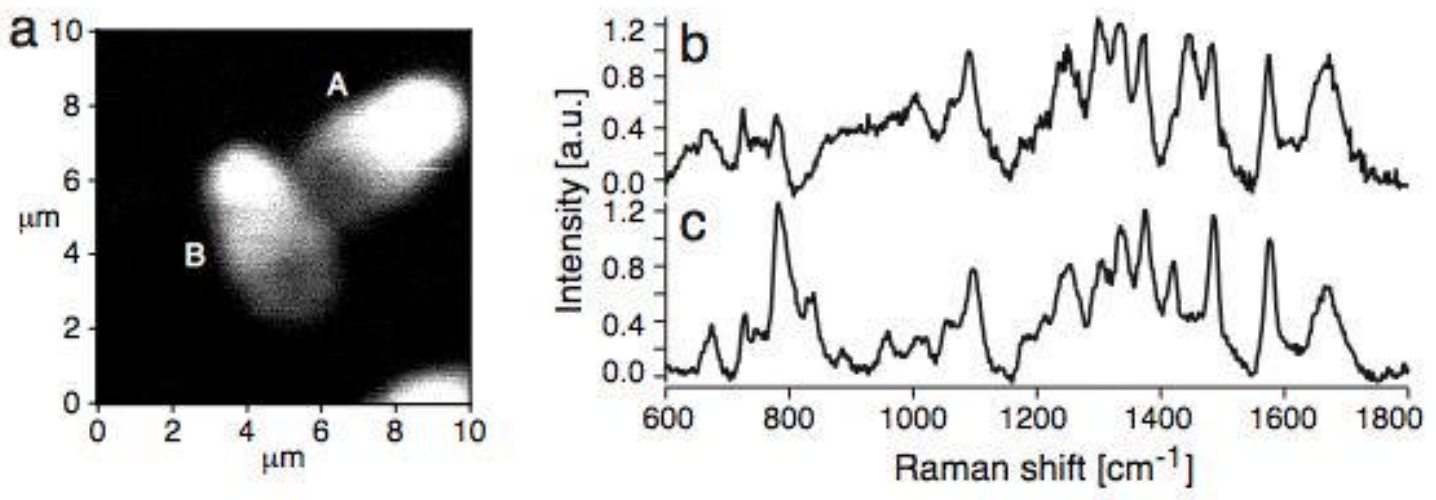

Fig. 2: (a) Confocal autofluorescence image of a normal human sperm cell head (A) and a pear-shaped sperm cell head (B) immobilized on a quartz optical flat. (b) Spontaneous micro-Raman spectrum of the central part of the normal sperm cell head A.

(c) Spontaneous micro-Raman spectrum of a calf-thymus DNA gel.

We have then transferred and extended the experience gained from these studies to the combination of confocal single molecule microscopy with atomic force microscopy (AFM) [4]. SER tips were first produced by depositing thin gold or silver films to scanning force microscope tips. Our first approach to simply deposit these films onto existing tips in a high vacuum chamber, however, were ill-fated. As we had to realize very quickly, SER spectroscopy with AFM tips requires that the tips and metal films be treated with the highest degree of cleanliness, because of the unsurpassed sensitivity of the technique. Tips have to be clean very rigorously in a UV ozone system before they can be used for SER microscopy, and the metal films have to be deposited with great care in a cryo-vacuum deposition system. After these steps, however, we were able to obtain position-dependent SER spectra from single cells that show characteristic differences in their protein and DNA Raman lines (cf. Figure 3).
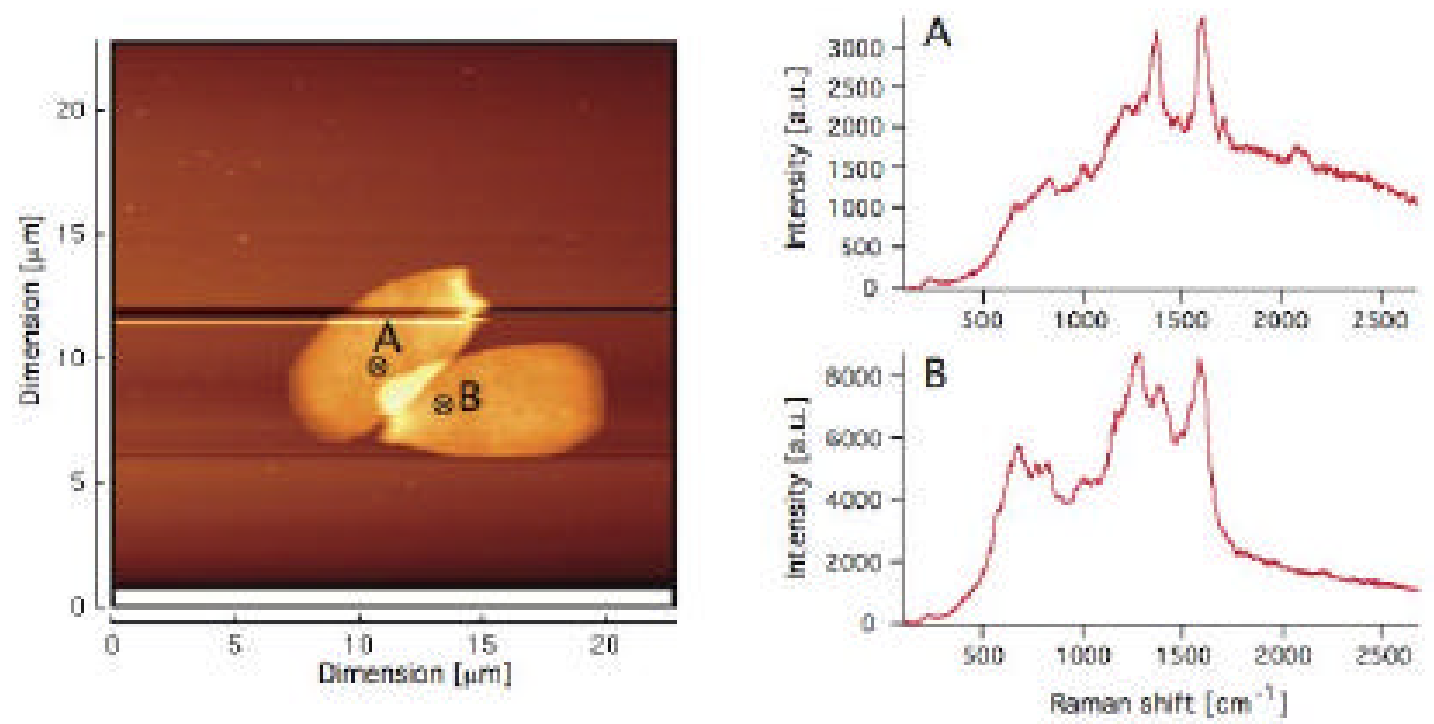

Fig. 3. Topographic image of two partly overlapping bull sperm spectra. The SERS spectra in (A) and (B) were obtained at their specific locations on the cell surfaces as indicated in the topographic image. Note the differences in the spectra, which indicate an abundance of protein in position (A) (strong peak at $1442 \mathrm{~cm}^{-1}$ ) and a higher local DNA content in (B) as evidenced by the strong peaks from purine bases.

Another problem, however, is the softness of the deposited gold layer and the extreme sensitivity of these tips to contaminations. This leads to the fact that through the course of a raster-scan of the surface 
the tip can easily get contaminated, which will render it useless. This, problem, however, can be largely avoided by using the so-called "tapping" mode of AFM [4]. Also, another complication is the fact that for so far unknown reasons only about 1 out of 20 tips shows the necessary strong field-enhancement, which makes the process of tip-fabrication rather elaborate and time-consuming. For these reasons, we have primarily focused our attention to the use of gold or silver nanoparticles as probes for single biomolecules, which has also led to a new invention of SERS nanosensors [5]. This approach is currently being pursued and follow-up funding has been generated through DOE NA-22 support. Several proposals to external funding agencies (NIH NIBIB, DOE OBER) have also been submitted or are currently in preparation.

\section{References}

[1] Huser, T., M. Yan

Aggregation Quenching in Thin Films of MEH-PPV Studied by Near-Field Scanning Optical

Microscopy and Spectroscopy

Synthetic Metals 116, 333 (2001)

UCRL-JC-138638

[2] Huser, T., M. Yan, L. J. Rothberg

Single chain spectroscopy of conformational dependence of conjugated polymer photophysics

Proceedings of the National Academy of Sciences of the United States of America

97, 11187 (2000)

UCRL-JC-138711

[3] T. Huser, C.A. Orme, C.W. Hollars, M.H. Corzett, and R.L. Balhorn

Raman Spectroscopic Study of Protein-induced DNA Packaging in Individual Human Sperm Cells In preparation

[4] A. Noy, T.R. Huser

A combined force and photonic probe microscope with single molecule sensitivity

Review of Scientific Instruments, in press (2003)

UCRL-JC-149425

[5] C.E. Talley, T.R. Huser, C.W. Hollars, S.M. Lane, J. H. Satcher

Invention Case No.: IL-11108 